\title{
DIFICULDADES DE APRENDIZAGEM NA LEITURA E NA ESCRITA COM ÊNFASE NA DISLEXIA
}

\section{ARTIGO ORIGINAL}

NETA, Francisca Sales de Souza ${ }^{1}$

SILVA, Clesia de Lima ${ }^{2}$

COSTA, Daniele de Souza da ${ }^{3}$

${ }_{1}^{1}$ Pós-Graduada em Psicopedagogia Institucional e Clínica - Faculdade do Maciço de Baturité (FMB); Pós-Graduada em Alfabetização e letramento - Faculdade do Vale Elvira Dayrell/Instituto Pedagógico Brasileiro (FAVED/IPEBRAS); Pós-Graduada em Educação Infantil e Séries Iniciais - Instituto Pedagógico de Minas Gerais (IPEMIG); Pós-Graduanda em Educação Especial e Inclusiva e Neuropsicopedagogia Institucional e Clínica - Faculdade Venda Nova do Imigrante (FAVENI); Graduada em Licenciatura plena em Pedagogia - Instituto Superior de Educação de Personalizada (ISEP).

2 Pós-Graduada em Educação Infantil e Anos Iniciais, Ludo pedagógica e Literatura na Educação Infantil e Anos Iniciais, Ludo Pedagógica e Educação Especial - A Faculdade Futura. Mantida pelo Institucional e Clínica, Educação e Tecnologia de Votuporanga - SP, Faculdade Venda Nova do Imigrante (FAVENI); Graduada em Licenciatura plena em Pedagogia - Faculdade Evangélica do Piauí (FAEPI); PósGraduanda em Educação Especial e Inclusiva Múltiplas Deficiências - Centro de Ensino Superior Dom Alberto Santa Cruz do Sul/RS.

${ }^{3}$ Pós-Graduada em Alfabetização e Letramento - Instituto Pedagógico Brasileiro (IPEBRAS); Pós-Graduada em Educação Infantil - Instituto Pedagógico de Minas Gerais (IPEMIG); Pós-Graduanda em Gestão Escolar (Administração, supervisão, orientação e inspeção) - Faculdade Venda Nova do Imigrante (FAVENI); PósGraduanda em Educação Especial e Inclusiva e Neuropedagogia Institucional e 
SILVA, Edilma Rejane Rodrigues de Menezes ${ }^{4}$

SANTOS, Niege das Graças de Sousa Mouras dos ${ }^{5}$

NETA, Francisca Sales de Souza. Et al. Dificuldades de aprendizagem na leitura e na escrita com ênfase na dislexia. Revista Científica Multidisciplinar Núcleo do Conhecimento. Ano 05, Ed. 11, Vol. 23, pp. 93-116. Novembro de 2020. ISSN: 24480959, Link de acesso:https://www.nucleodoconhecimento.com.br/semcategoria/enfase-na-dislexia

\section{RESUMO}

O presente trabalho tem como objetivo analisar as principais dificuldades de aprendizagem na leitura e na escrita encontrada nos anos iniciais do ensino fundamental. Encontrar as causas e consequências dessas dificuldades, um método a construir mecanismo que possam superá-las e atender as reais necessidades dos alunos. Através desta pesquisa, pretende-se mostrar as dificuldades de aprendizagem na leitura e na escrita, os recursos que podem ser utilizados para solucionar uma condição que enfrenta com relação a essas dificuldades. Portanto, a missão da escola é oferecer aos alunos objetivos para que eles aprendam e possibilitar aos mesmos, atuar criticamente em seu meio social. Mas, nem sempre as escolas conseguem alcançar uma educação de qualidade onde todos possam crescer e associar novos conhecimentos, pois há alunos com aptidões diferentes. Cada criança é única, a dificuldade de aprendizagem está relacionada a individualidade, portanto, há vários níveis de aprendizagem numa mesma turma. Cabe ao professor descobrir

Clínica - Faculdade Venda Nova do Imigrante (FAVENI); Graduada em Licenciatura plena em Pedagogia - Instituição Superior de Educação de Personalizada (ISEP).

4 Pós-Graduada em Educação Infantil e Letramento e em Educação Especial e Atendimento Educacional Especializado - Faculdade do Vale Elvira Dayrell/Instituto Pedagógico Brasileiro (FAVED/IPEBRAS); Graduada em Pedagogia - Universidade Federal do Rio Grande do Norte (UFRN).

${ }^{5}$ Orientadora. 
possibilidades e incentivá-los a desenvolver habilidades na construção do

conhecimento. É fundamental que haja um maior envolvimento e integração de todos que participam do método de ensino-aprendizagem. Para superar as causas e consequências das dificuldades de aprendizagem encontradas por esses alunos na leitura e na escrita. Portanto, é necessário a busca de compreender o que está acontecendo com os mesmos e aplicar a metodologia que possa contribuir e ajudar no desenvolvimento, permitindo que cada indivíduo seja integrado na sociedade letrada.

Palavras-chave: Dificuldade, leitura, escrita.

\section{INTRODUÇÃO}

As dificuldades de aprendizagem na leitura e escrita que se apresentam na infância podem permanecer uma vida inteira acarretando prejuízos nas áreas de desenvolvimento pessoal, familiar, social e cultural. Destacar as dificuldades de aprendizagem na leitura e na escrita é um desafio que se deve abordar de forma compreensiva, conduzindo a uma conexão que leve a algo compreensível. Portanto, cabe ao professor diagnosticar o tipo de problema que o seu aluno está enfrentando, quando o professor perceber que seu aluno não está tendo um bom rendimento escolar, é preciso entender os fundamentos dessa complexidade, ao invés de achar que o seu aluno é incapaz. A importância da leitura e escrita no processo de desenvolvimento da criança são fatores essenciais no desenvolvimento intelectual, pessoal e social abrangendo percepções primordiais de visão do mundo.

A importância da leitura e escrita no contexto educacional contribui para o desenvolvimento de aptidões da criança buscando evidenciar a utilidade da leitura e escrita para o seu enriquecimento pessoal, cultural e social tornando-o sujeito crítico, inserido de modo dinâmico na sociedade.

É responsabilidade da escola inserir o aluno na cultura letrada, mas é o ser humano que constrói o seu próprio conhecimento durante todos os momentos de sua vida, dentro e fora da escola. Independentemente do suporte, é dever da escola oferecer 
aos alunos caminhos de aprendizagem, sendo ele uma criança que apresente dificuldade de aprendizagem ou não, pois ela também tem o direito de adquirir conhecimentos de incapacidade, que leva a frustração. Faz-se necessário que o professor olhe para o seu aluno de forma primordial, desenvolvendo técnicas que permita que a criança tenha sucesso na sua aprendizagem.

O presente trabalho está dividido em introdução, no segundo capítulo destaca as dificuldades de aprendizagem na leitura e na escrita, assim como os conceitos de cada um desses processos. A dificuldade de aprendizagem passa a ser percebida no instante que a criança é inserida na escola, por ser um momento de desenvolvimento em que a criança deve adquirir aptidão. A complexidade do aprendizado em leitura e escrita é um dos maiores fatores que interferem na aprendizagem e na autoestima do aluno. Portanto, o professor como mediador do processo ensino-aprendizagem, deve transmitir a criança confiança e compreensão diante das suas dificuldades.

É fundamental que o professor busque métodos adequados para facilitar a compreensão e o aprendizado do seu aluno. Sendo assim, é necessário motivá-los informando das suas habilidades e competências, para que a realização das atividades aconteça de forma satisfatória.

O terceiro capítulo fala sobre a importância da leitura e da escrita no processo de ensino-aprendizagem, como também, o papel do professor. É importante compreender que a leitura é uma das oportunidades mais acessíveis na formação do indivíduo. A leitura é fundamental no processo de construção do conhecimento, possibilitando relações dos nossos próprios conceitos e proporcionando-os a isenção no convívio social. $O$ indivíduo que pratica o hábito de leitura, adquiri mais conhecimentos, compreendendo o mundo e se torna capaz de atuar como cidadão. $O$ domínio da leitura está na capacidade do sujeito colocar em prática os seus conhecimentos necessários para dominar a técnica do ler e escrever nas mais variadas situações sociais no mundo letrado.

A interpretação da leitura é capaz de transformar a vida do indivíduo, proporcionando a constante busca de conhecimento e necessitando afirmar sua posição social e 
cultural. O professor, é o profissional mediador do conhecimento, sendo assim, a escola deve incentivar a leitura, de forma que colabore para que o aluno tenha um bom desempenho em todos os campos da compreensão.

A escola é um lugar amplo de conhecimento onde deve garantir o direito a aprendizagem e participação do aluno acreditando ser possível contribuir com esse processo. A presente pesquisa tem o objetivo de analisar as dificuldades de aprendizagem na leitura e na escrita, buscando destacar e compreender esses dois processos importantes no contexto social do aluno. Como fonte de apoio foi encontrada obras de autores renomados como Magda Soares (2004), Emília Ferreiro 1985), Maria Helena Martins (1982), Paulo Freire (1989), Jean Piaget (1973) e Lev Vygotsky (1987). A presente pesquisa se desenvolveu através de estudos que pudesse trazer contribuições para resolução dos problemas de dificuldades de aprendizagem na leitura e na escrita.

\section{DIFICULDADES DE APRENDIZAGEM NA LEITURA E NA ESCRITA COM ÊNFASE NA DISLEXIA}

A dificuldade de aprendizagem possui múltiplas causas incluindo a metodologia de ensino inadequado as necessidades da criança, causas de ordem emocional e outros quadros de diagnósticos. Indivíduos que apresentam dificuldades de aprendizagem tem potencialidade, tal como outros indivíduos de inteligência mediana, mas muitas vezes são impossibilitados de conseguir esse potencial.

A aprendizagem e a construção do conhecimento deveriam acontecer de maneira natural e prazerosa, mas o que se percebe, é que muitos alunos do ensino fundamental apresentam maior dificuldades de aprendizagem na leitura e na escrita. Se essas dificuldades não forem percebidas e corrigidas causarão problemas no desempenho escolar e, consequentemente, no futuro dessas crianças.

[...] letramento é o que as pessoas fazem com as habilidades de leitura e escrita, em um contexto específico, e como essas habilidades se relacionam com as necessidades, valores e práticas sociais, ou seja, é o conjunto de práticas sociais relacionadas à leitura e à escrita em que 
os indivíduos se envolvem em seu contexto social. (SOARES, 2001, p. 72)

A aprendizagem da leitura e da escrita não acontece da mesma forma para todas as crianças e, dependendo da maneira como o processo de ensino é conduzido, pode causar dificuldades na aprendizagem de modo geral. O objetivo mais importante da alfabetização é ensinar a escrever, e a criança com necessidades de aprendizagem na leitura e na escrita necessita de um cuidado especial. Um dos maiores problema que acontece na escola é que ela ensina a escrever sem ensinar o que é escrever, podendo, portanto, gerar dificuldades de aprendizagem. Neste sentido, Soares (2001, p. 48) completa dizendo que

O domínio da leitura está na capacidade de o sujeito colocar em ação todos os componentes necessários para dominar a língua numa sociedade letrada. Não basta apenas dominar a técnica de ler e escrever precisa desenvolver competências.

Muitas crianças têm dificuldades em relação a leitura porque não aprenderam durante sua escolarização a interpretar o que leem e o que está escrito, e carregam essa dificuldade por toda vida. Alguns professores, ao invés de enfrentarem as dificuldades junto com o aluno, livram-se desta responsabilidade passando o aluno para a série seguinte podendo assim, aumentar a dificuldade de aprendizagem apresentada. $O$ professor deve instituir metas e ferramentas eficazes que preencham as lacunas existentes na alfabetização desse aluno e reforçar todo e qualquer desempenho escolar por menor que seja.

\subsection{CONCEITOS DE LEITURA}

A leitura é um processo de compreensão de mundo que abrange características necessárias do homem, levando a sua qualidade simbólica e capacidade de interação com outra palavra no contexto social.

A leitura deve ser feita de um jeito divertido para todas as crianças. Ler para crianças, na infância, traz benefícios transformando-os em facilitadores de aprendizagem, mostram maior interesse na alfabetização e maior habilidade em se comunicar. Ler e contar histórias são formas de desenvolver o gosto pela fantasia, incentivando nos 
pequenos aspectos que dizem respeito a sua potencialidade criativa. O principal suporte para a alfabetização é a leitura. A escola possui um papel importante no desenvolvimento do hábito de ler. Instruir a criança a decodificar a leitura, é fundamental para formar bons leitores. De acordo com os Parâmetros Curriculares Nacionais (1997),

A leitura tem como finalidade a formação de leitores competentes e, consequentemente, a formação de escritores, pois a possibilidade de produzir textos eficaz tem sua origem na prática de leitura, espaço de construção da intertextualidade e fonte de referências modalizadoras. (PCNs, 1997, p. 53),

O leitor tem competência para construir suas faculdades intelectuais, mas também se limita aos significados dos textos e suas condições de usos. Os conceitos de leitura variam, assim como variam os conceitos de escrita e, constituem fatores importantes nesta variação, a perspectiva da escrita em relação a língua falada. Os conceitos da leitura são importantes para as práticas pedagógicas no processo de alfabetização. De cordo com Martins (1982, p. 30) "o ato de ler se refere tanto a algo escrito quanto a outros tipos de expressão do fazer humano, caracterizando-se como acontecimento histórico e estabelecendo uma relação igualmente histórica entre o leitor e o que é lido". O processo essencial da leitura consiste na elaboração de hipóteses realizada na antecipação e na compreensão do conteúdo do texto. A leitura atribui o sentido do texto, mediante a articulação de hipóteses e antecipações, no qual interferem as intenções do leitor que o transmitem ao realizar a leitura.

A leitura em voz alta é muito importante para que as crianças se familiarizem com o texto antes mesmo de chegar a uma leitura independente. O nível da leitura independente acontece quando a criança ler com fluência, compreendendo o texto e reconhecendo as palavras de forma rápida. Assim, "se uma criança sabe ler, mas não é capaz de ler um livro, uma revista, um jornal, se sabe escrever palavras e frases, mas não é capaz de escrever uma carta, é alfabetizada, mas não é letrada". (SOARES, 2000a).

O prazer da leitura deve ser despertado logo na infância. Ler faz parte da formação cultural de cada indivíduo. A leitura estimula a imaginação, proporciona a descoberta 
de diferentes hábitos e culturas, amplia o conhecimento e enriquece o vocabulário. A primeira experiência da criança com a leitura deve começar na família, pois facilita as aprendizagens escolares. A leitura contribui para a formação do sujeito tornando-o um cidadão mais consciente, com uma visão ampla do mundo, e ajudando-o na transformação de si e da realidade em que vive. A prática da leitura tem como finalidade a formação de leitores e escritores competentes, pois a possibilidade de produzir textos tem sua origem na prática da leitura. A leitura e a escrita como prática social é sempre um meio para múltiplas finalidades, pois ler é uma necessidade pessoal que deve ser incentivada e proporcionada pela escola. Martins (1982, p. 22) cita que "A leitura está geralmente restrita à decifração da escrita, sua aprendizagem, no entanto, liga-se por tradição ao processo de formação global do indivíduo, à sua capacitação para o convívio e situação social, política, econômica e cultural”.

Uma leitura personalizada ajuda a criar um contexto enunciado do conto, servindo assim de motivação para que a criança participe da leitura com interesse facilitando a compreensão e influenciando a forma da criança falar com o adulto. Para compreender um texto, as crianças necessitam assimilar as informações nele apresentado com seu conhecimento prévio. Depois de ouvir uma leitura, as crianças desenvolvem na memória algum tipo de apresentação do texto ouvido. É de suma importância dar prioridade absoluta à leitura desde a alfabetização. O melhor que a escola pode oferecer ao aluno é a leitura.

\subsection{DEFINIÇÕES DA ESCRITA}

Para começar, é importante ressaltar que a aprendizagem da escrita seja afetiva, a criança precisa perceber que a aprendizagem na qual está adquirindo é significativa para ela. É importante que a criança desde início aprenda e escrever bem, que conheça cada letra e a forma de executá-la corretamente. Para ter sucesso na escrita a criança, precisa conhecer a estrutura da letra. É importante que a criança aprenda o que é escrita e, as maneiras possíveis de escrever, a qualidade dos símbolos que permita decifrar, as relações entre letras e sons tornam possível a leitura. É plausível destacar o que Ferreiro (2001) diz sobre a escrita: 
A escrita pode ser concebida de duas formas muito diferentes e conforme o modo de considerá-la. As consequências pedagógicas mudam drasticamente e a escrita pode ser considerada como uma representação da linguagem, ou como um código de transcrição gráfica das unidades sonoras. (FERREIRO, 2001, p. 10)

A linguagem escrita precisa ser abordada na pré-escola, porque a criança antes mesmo de entrar para a escola formal já possuem conhecimentos. O contato precoce com a linguagem escrita contribui para reflexão da potencialização da sua aprendizagem. Uma prática pedagógica de diferentes suportes da escrita na sala de aula é importante porque permite que a linguagem escrita sirva de várias funções, e que o conhecimento das funções promove o desenvolvimento dos aspectos figurativos e da linguagem escrita.

Ferreiro (2001) afirma ainda que

A invenção da escrita foi um processo histórico de construção de um sistema de representação, não um processo de codificação. Uma vez construído, poder-se-ia pensar que o sistema de representação é aprendido pelos novos usuários como um sistema de codificação. (FERREIRO, 2001, p. 12)

A alfabetização é um processo, que não se limita apenas em ler e escrever símbolos do alfabeto, mas compreender a estrutura da língua e a forma como é utilizada. $O$ aprendizado no processo de alfabetização realiza-se quando o educando entente que a escrita é a correspondência grafema-fonema.

A escrita compõe-se de conhecimento para criança criar suas próprias regras, aonde a criança vai criando e testando as hipóteses de como se escreve as palavras. Ferreiro e Teberosky (1985), quanto esta, enfatiza que novas informações,

[...] vão desestabilizando a hipótese silábica até que a criança tem coragem suficiente para se comprometer em seu novo processo de construção. $O$ período silábico-alfabético marca a transição entre os esquemas prévios em vias de serem abandonados e os esquemas futuros em vias de serem construídos. Quando a criança descobre que a sílaba não pode ser considerada como unidade, mas que ela é, por sua vez, reanalisável em elementos menores, ingressa no último passo da compreensão do sistema socialmente estabelecido. E, a partir daí, descobre novos problemas: pelo lado quantitativo, se não basta uma 
letra por sílaba, também não pode estabelecer nenhuma regularidade duplicando a quantidade de letras por sílaba (já que há sílabas que se escrevem com uma, duas, três ou mais letras); pelo lado qualitativo, enfrentará os problemas ortográficos (a identidade de som não garante a identidade de letras, nem a identidade de letras a de som). (FERREIRO e TEBEROSKY, 1985, p. 13-14).

\subsection{COMO MINIMIZAR OS PROBLEMAS ATUAIS NA QUALIDADE DE LEITURA E ESCRITA}

As crianças não nascem com dificuldades escolares, elas aparecem ao longo do processo de aprendizagem. Assim, é necessário possibilitar ações reflexivas em torno dos educandos com problemas de aprendizado, para que eles apresentem a capacidade de aprender. Em conformidade com Vygotsky (1987, p. 101) "o aprendizado adequadamente organizado resulta em desenvolvimento mental e põe em movimento vários processos de desenvolvimento que, de outra forma, seriam impossíveis de acontecer".

A aprendizagem é um processo ativo, sendo consequência da relação entre professoraluno. Necessitamos compreender que aprendizagem é cotidianamente construída e o professor é responsável por oferecer condições adequada para que a mesma seja desenvolvida.

A compreensão do professor é imprescindível sobre quais fatores interferem na aprendizagem da criança, buscando constantemente as questões que atingem o processo na construção do conhecimento. Nos termos de Fonseca (1995, p. 81-82) "O professor é responsável por criar uma estrutura de envolvimento educacional de forma a promover as capacidades de aprendizagem dos alunos, provocando, reforçando e otimizando os seus potenciais de adaptabilidade e sociabilidade".

Esse processo de aprendizagem acontece através da transmissão de conhecimento. O professor deve transmitir à criança confiança e compreensão, evitando transmitir aflição e angústia diante das dificuldades que ela apresenta. É importante que o educador transmita à criança que entenda a razão das suas dificuldades de aprendizagem e busque métodos adequados para facilitar a compreensão e o 
aprendizado. Sendo assim, buscando conteúdos que sejam significativos e utilizando metodologias que possibilitem a criança fazer relação entre o que está aprendendo e a sua vida. Nesse sentido, Vygotsky (1991, p. 97) ressalta que "A aprendizagem é o resultado da interação dinâmica entre a criança com o meio social, sendo que o pensamento e a linguagem recebem influência do meio que convivem".

É necessário que haja afetividade na relação entre professor e aluno, pois a confiança entre ambos possibilita o professor identificar as necessidades do seu aluno e reformular sua prática metodológica para uma aprendizagem eficiente.

Precisa-se que o educador busque uma metodologia onde o processo de ensinoaprendizagem aconteça de forma conjunta. É necessário que o professor trabalhe metodologias inovadoras com o intuito de proporcionar aos alunos maior motivação e participação, facilitando a compreensão e o aprendizado.

\section{A IMPORTANCIA DA LEITURA NO PROCESSO ENSINO- APRENDIZAGEM}

O primeiro contato das crianças com a leitura acontece por meio da leitura auditiva, onde alguém lê em voz alta e outras pessoas acompanham a leitura de forma silenciosa. A criança acompanha ouvindo e, certamente, construindo associação com a reprodução de mundo que ela já possui. A leitura tem vários processos, um deles é orientar o aluno a realizar uma leitura significativa para facilitar a própria compreensão do texto. Dessa maneira, "Aprender a ler começa com o desenvolvimento do sentido das funções de linguagem escrita. Ler é buscar significado e o leitor deve ter um propósito para buscar significado no texto". (FERREIRO, 1987, p. 21).

A importância da leitura no processo ensino-aprendizagem, ocorre diante da necessidade de desenvolvimento no processo educativo. A prática da leitura é de suma importância, pois é através dela que adquirimos conhecimentos capazes de nos ajudar no desenvolvimento, enriquecendo nossos pensamentos, aprimorando nosso vocabulário. $\mathrm{O}$ hábito da leitura deve ser estimulado ainda na infância, para que o indivíduo aprenda desde pequeno que ler é algo importante e, acima de tudo, 
prazeroso. Quanto mais cedo, histórias orais e escritas entrarem na vida da criança, maiores as chances de ela gostar de ler. Uma leitura de qualidade representa a oportunidade de ampliar a visão do mundo. Através da leitura o homem pode tomar consciência das suas necessidades, promovendo assim a sua transformação e a do mundo. A compreensão é o instrumento que dará suporte necessário para aquisição de saberes na formação de um cidadão crítico para atuar na sociedade.

Em Freire (1989), vamos encontrar o seguinte esclarecimento,

Em "A importância do ato de ler" trabalha a temática da leitura, discutindo sua importância, explicitando a compreensão crítica da alfabetização, reforçando que a alfabetização demanda esforços no sentido de compreensão da palavra escrita, da linguagem, das relações do contexto de quem fala, lê e escrever a relação entre de mundo e leitura de palavra. (FREIRE, 1989, p. 69).

Compete ao professor, incentivar seus alunos o hábito de leitura, o desenvolvimento do senso crítico e do raciocínio lógico. A leitura melhora o aprendizado dos alunos, pois estimula o bom funcionamento da memória, aprimorando a capacidade interpretativa, pois mantém o raciocínio ativo, além de proporcionar ao leitor um conhecimento amplo e diversificado sobre os diversos assuntos, ela possibilita melhor compreensão do mundo, permitindo ao indivíduo uma visão crítica do mundo. É preciso dar atenção especial as crianças, e inserir o hábito da leitura desde cedo. A partir do incentivo que podemos construir esse hábito, resultará em adultos leitores. É importante proporcionar às crianças um espaço rico para o incentivo à leitura. Como descrito por Martins (1982),

Aprender a ler significa aprender a ler o mundo, e a função do educador não seria precisamente a de ensinar a ler, mas a de criar condições para o educando realizar a sua própria aprendizagem, conforme seus próprios interesses, necessidades, fantasias. (MARTINS, 1982, p. 34).

A leitura é uma experiência que adquirimos no decorrer de nossa vida, é fundamental não apenas na formação do aluno, mas também na formação do cidadão, desta forma, a escola tem o objetivo de ensinar e educar para a sociedade, proporcionando conhecimentos básicos que venha contribuir para a formação de um homem crítico, 
capaz de compreender as características sociais, culturais e naturais do qual está inserido. Como destaca Freire (1989),

a "leitura de mundo precede a leitura da palavra, daí que a posterior leitura desta não possa prescindir da continuidade da leitura daquele", uma vez que ela seria a ponte para o progresso educacional eficiente, proporcionando a formação integral do indivíduo. (FREIRE, 1989, p.1112).

A maior parte dos conhecimentos humanos é obtida por intermédio da leitura, por isso é preciso ler muito, continuadamente e com regularidade, pois ler constantemente significa aprender a conhecer, interpretar, decifrar e distinguir os elementos fundamentais dos secundários.

A leitura é uma das mais importantes tarefas que a escola tem que ensinar, mais para isso o professor deve ter consciência da necessidade, além de praticar com eficiência o hábito da leitura. É preciso ensinar todas as crianças a ter hábitos de leitura desde a infância, para que o indivíduo aprenda que ler é algo importante e prazeroso, assim ele será um adulto culto e dinâmico. Em conformidade com Silva (2003) que

Refere-se a leitura como sendo um elemento fundamental para adquirir saber. A leitura é um componente da educação e a educação, sendo um processo, aponta para a necessidade de buscas constantes de conhecimento. (SILVA, 2003, p. 19).

A leitura é algo comercial para a aprendizagem do ser humano, pois é através dela que podemos enriquecer nosso vocabulário e obter conhecimento. $O$ ato de ler é um processo de compreensão, de entender o mundo a partir de uma característica particular ao homem.

Para Bamberger (2002, p. 32) "A leitura suscita a necessidade de familiarizar-se com o mundo, enriquecer as próprias ideias e tem experiências intelectuais, o resultado é a formação de uma filosofia da vida, compreensão do mundo que nos rodeia". Portanto, é necessário ensinar as crianças a desenvolver hábitos de leituras, para que desperte o prazer de e aprenda a analisar e compreender a vida em uma sociedade letrada. 


\subsection{IMPLICAÇÕES NA DIFICULDADE DA LEITURA}

A leitura é a atividade fundamental desenvolvida pela escola para a formação do aluno. Há muitas crianças com dificuldades de aprendizagem que têm problemas com a leitura. A falta de interesse pela leitura é uma comprovação que a mesma não foi desenvolvida de forma significativa na infância, e deve-se, em grande parte ao tipo de literatura que foi oferecida as crianças, não considerando o interesse e a faixa etária dos alunos, tornando assim, o contato com os livros desagradável.

Na opinião de Ferreiro e Teberosky (1985),

As crianças aprendem a ler participando das atividades de uso da escrita junto com as pessoas que dominam esse conhecimento. Aprendem a ler quando acham que podem fazer isso. É difícil uma criança aprender a ler quando se espera dela o fracasso. É difícil também a criança aprender a ler se ela não achar finalidade na leitura. (FERREIRO e TEBEROSKY, 1985, p. 72)

Não existe um método ou tipo de material adequado para todas as crianças, portanto, quanto mais conhecimento e recursos o professor tiver, mais efetivo poderá ser o seu trabalho. É necessário manter as crianças motivadas para a leitura. A maioria das crianças não tem a motivação, nem o acesso ao material de leitura em casa. Como descrito por Ferreiro (1993),

Faz necessário criar um ambiente alfabetizador havendo um "canto ou área de leitura" onde se encontrem não livros bem editados e ilustrados, como qualquer tipo de material que contenha a escrita (jornais, revistas, dicionários, folhetos, embalagens de medicamentos etc.). Quanto mais variados esse material, mais adequado para realizar diversas atividades de exploração, classificação, busca de semelhanças e diferenças para que o professor, ao lê-los em voz alta, dê informações sobre" o que se pode esperar de um texto" em funções de caracterização do objeto que veicula. Insisto: a variedade de materiais não é só recomendável, no meio rural, mais em qualquer lugar onde realize uma ação alfabetizadora. (FERREIRO 1993, p. 33)

As crianças com alterações da percepção visual e auditiva, apresentam dificuldades na aprendizagem da leitura, porque as informações chegam ao cérebro de forma destorcida. Essa criança tende a desenvolver uma baixa autoestima e rejeição por 
tudo que tenha relação a leitura. O professor deve trabalhar levando em consideração a idade, a maturidade e competência da criança.

Outra causa frequente do surgimento de dificuldade na leitura é um ensino inadequado. Isto se refere basicamente à utilização de uma metodologia incompatível com as necessidades ou fragilidade da criança. É necessário que, os professores tenham a melhor preparação possível e utilizem estratégias efetivas no manejo da classe, assim como meios apropriados para individualizar o ensino, faz-se necessário que o professor reveja seus métodos de ensino, para que o aluno possa aprender.

O ensino da leitura num ritmo errado, é outra causa de impedimento no aprendizado. Muitas vezes ensina-se com ritmo acelerado, sem os reforços necessário, suficientes ao conhecimento das palavras de uso mais frequente e dos elementos fonéticos mais importante, portanto, não atingem o domínio básico para o processo de leitura.

As Classes superlotadas nos primeiros anos de escolaridade não contribuem para uma aprendizagem adequada da leitura. É importante tentar dar o máximo de atenção individualizada possível, focando o ensino na modalidade de aprendizagem preferencial da criança.

Um dos maiores fatores que exerce maior influência sobre o sucesso ou fracasso da aprendizagem da leitura, é a relação professor-aluno. É necessário que o professor demostre afeto autêntico por seus alunos, confiando nas suas habilidades para melhorar suas competências leitoras. Dessa maneira, os PCNs (1997, p.54) menciona que "um leitor competente só pode constituir-se mediante a uma prática constate de leitura de textos de fato, a partir de um trabalho que deve se organizar em torno da diversidade de textos que circulam socialmente".

A criança aprende ler lendo, portanto, o professor deve fazer com que esse aprendizado seja fácil e divertido, sendo necessário que o professor reveja seus métodos de ensino, para que o aluno vivencie cada situação e aprenda a compreender e assimilar melhor o que Ihes é ensinado. Fazer da leitura uma aprendizagem fácil, significativa, útil, divertida e frequente. 


\subsection{TRANSTORNO DE APRENDIZAGEM: DISLEXIA}

A dislexia é um distúrbio específico de aprendizagem na leitura e na escrita que, trabalhada de maneira adequada, pode ser superada e a criança disléxica terá uma vida normal. A identificação precoce é o segredo do sucesso na aprendizagem da leitura. Portanto, o disléxico deve ser tratado com carinho para que ele tenha um bom desenvolvimento na aprendizagem. Sendo assim, não se deve repreender um disléxico quando ele cometer erros, pois se repreendido ele ficará constrangido e apresentará dificuldades de tentar mais uma vez.

O professor deverá motivá-lo a sempre tentar acertar, despertar no seu aluno interesse pelo saber, desenvolvendo sua criatividade e capacidade de construir. Fonseca (1995) afirma,

Somos de opinião que o professor primário deve ele próprio construir os seus instrumentos de diagnóstico pedagógico (diagnóstico informal) a fim de conduzir a sua atividade mais coerentemente... é do maior interesse o uso de instrumentos que permitam detectar precocemente qualquer dificuldade de aprendizagem, pois só assim uma intervenção psicopedagógico pode ser considerada socialmente útil, pois quanto mais tarde for identificada a dificuldade, menos hipóteses haverá para solucionar corretamente. (FONSECA, 1995, p.35)

A dislexia é um dos termos mais utilizados dentre as complexibilidades do aprendizado. De acordo com a Universidade Luterana do Brasil (ULBRA) apud Oliveira (2008, p. 167) "A dislexia pode ser definida como distúrbio ou transtorno de aprendizagem na área da leitura, escrita e soletração. A dislexia é o distúrbio de maior incidência nas salas de aula". Desta forma, não é considerada uma doença, e sim, uma disfunção neurológica, onde as informações fazem caminho mais longo e demora mais tempo para ser processada, e assim, prejudicando no aprendizado da leitura e escrita.

Os professores, muitas vezes, não estão preparados para lidar com esses alunos, pois se sentem impotentes quanto a elaboração de uma metodologia adequada para trabalhar com esses alunos. 
Para Drouet (2006),

O professor tem o primeiro mês de aula para conhecer o aluno e saber qual método usar para obter um bom desempenho em suas aulas e o portador de alguns distúrbios não sofra tanto. $O$ professor de primeiro grau não tem a formação necessária para diagnosticar graves distúrbios de aprendizagem. Através de observação, ele poderá detectar diferenças ou falhas no desempenho dos seus alunos. (DROUET, 2006, p. 28)

É importante que os pais, juntamente com a escola, elaborem estratégias para trabalhar os conteúdos de maneira adequada para que a criança se sinta motivada. É necessário que a criança disléxica receba muito carinho e atenção como forma de estímulo para seu desenvolvimento e aprendizagem. Assim, quanto mais cedo identificar na criança os sinais de dificuldades de aprendizagem, compreendendo as causas pelas quais uma criança tem dificuldade na sua lecto-escrita é de suma importância para encontrar estratégias adequadas para enfrentar suas dificuldades. Nem todas as crianças que têm dislexia apresentam as mesmas características, sendo a única característica comum, apresentarem dificuldade na leitura e escrita.

De acordo com Davis (2004),

a dislexia pode ser definida como, (...) um tipo de desorientação causada por uma habilidade cognitiva natural que pode substituir percepções sensoriais normais por conceituações; dificuldades com leitura, escrita, fala e direção, que se originam de desorientações desencadeadas por confusões com relação aos símbolos. A dislexia se origina de um talento perceptivo. (DAVIS, 2004, p.38).

A criança disléxica tem dificuldade de compreender o que está escrito e de escrever o que está pensando. Quando tenta expressar-se no papel, o faz de maneira incorreta fazendo com que o leitor não compreenda suas ideias. A criança disléxica não consegue reconhecer palavras que já tenha lido ou estudado. A leitura se torna um grande esforço para ela, pois toda palavra que ela lê, aparenta ser nova e desconhecida.

Para Lyon (1995 apud NICO; SOUZA, 2003), 
A dislexia é um entre vários distúrbios de aprendizagem, de origem constitucional caracterizado por dificuldade na codificação de palavras e insuficiência no processamento fonológico. Manifesta-se pela dificuldade em diferentes formas de linguagem, além da leitura, na escrita e na soletração.

\subsubsection{A IMPORTÂNCIA DA ESCRITA}

A escrita surgiu a partir da necessidade do homem de criar registros, armazenar dados para preservar a sua história. A escrita da humanidade se utilizou através de símbolos que com o passar do tempo foram evoluindo. O uso desses símbolos é considerado como uma das mais antigas manifestações de escrita produzida com a intenção de sua leitura.

O ato de ler é estabelecida pela escrita, assim, para tornar capaz de ler e escrever, o aluno necessita construir um conhecimento de natureza conceitual. Portanto, ela precisa entender não só o que a escrita representa, mas também de que maneira ela representa graficamente a linguagem. Consequentemente, cabe ao professor, juntamente com o seu aluno, pensar sobre as práticas da escrita, e verificar que marcas individuais limitam a possibilidade de leitura e que, para facilitar a comunicação entre as pessoas da sociedade, se instituiu um código e convencionou um desenho para as letras. No momento que a criança é inserida na escola, ela já tenta escrever fazendo rabiscos e por meios de rabiscos tenta escrever o que pensa. Muitas vezes, o professor não interpreta o que a criança quis escrever. Cabe ao professor perguntar ao aluno o que quer dizer o seu escrito e anotar as respostas, para poder acompanhar o seu desenvolvimento. O professor deve valorizar toda e qualquer tentativa da escrita, pois é nesse momento que a criança está compreendendo esse sistema da escrita.

Freire (1991), afirma:

A escrita é uma prática discursiva que na medida em que possibilita uma leitura crítica da realidade, se constitui como um importante instrumento de resgate da cidadania e que reforça o engajamento do cidadão nos movimentos sociais que lutam pela melhoria da qualidade de vida e pela transformação social. (FREIRE, 1991, p.68). 
O processor escolar não deve ensinar só a técnica de ler e escrever, mas desenvolver a aptidão do indivíduo, usar a escrita e prática letrada de circulação social. $\mathrm{Na}$ construção da escrita, é importante que as crianças construam seu próprio conhecimento. A escrita apresenta possibilidade de transmitir ideias, sentimentos e entendimentos de uma maneira nova que permanece. Para escrever é necessário que exista a necessidade, a qual deve ser acompanhada da capacidade de construir.

É importante que o professor organize situações de aprendizagem de forma desafiadora e significativa para que a criança possa ter uma influência reflexiva. Pois, quando o professor proporciona a leitura e a escrita autônoma, a criança, sentirá motivação desejando aprender cada vez mais, se esforçando para construir o seu próprio conhecimento. No processo de leitura e escrita é preciso deixar que a criança realize suas próprias descobertas, basta que o professor seja mediador da sua aprendizagem.

Segundo Ferreiro (2002),

A escola pode ser concebida como sistema de código de representação. Como código, os elementos já vêm prontos e com representação, a aprendizagem se constitui em uma construção pela criança. Ao trabalhar a escrita como código, o ensino privilegia os aspectos preceptivos e motor, relação gráfica e som e o significado é desconsiderado. (FERREIRO, 2002, p.10).

A construção da escrita é um procedimento de elaboração da criança, mediado pelo professor e com a interação dos colegas. O diálogo estabelecido pelo professor em sala de aula com as crianças, o tipo de leitura e a atividade, são fatores que influenciam no desenvolvimento da escrita do educando. A criança precisa ter contato com vários tipos de materiais escritos e ser estimulado a manipular esses materiais, para desenvolver a construção do seu conhecimento.

A apropriação do sistema da escrita é um processo que envolve o domínio do sistema alfabético-ortográfico quanto a sua compreensão e o uso permanente da escrita nas suas práticas sociais. 
Assim, a construção da escrita é um processo de elaboração pessoal da construção do conhecimento.

\subsubsection{AS DIFICULDADES DE APRENDIZAGEM}

Uma criança com dificuldade de aprendizagem não consegue assimilar como a maioria das outras crianças usando os mesmos métodos, porém, ela tem a capacidade intelectual para tal ato. Os problemas da falta de aprendizagem, não são a falta de capacidade intelectual, problemas emocionais ou instrução inadequada, no entanto estas condições podem acompanhar e agravar um problema na área de aprendizagem. Segundo Vygotsky (1979, p.139), "podemos concluir que a dificuldade de aprendizagem é um distúrbio psicológico que causa problemas a criança, quando esta se encontra no início do processo de alfabetização".

Cada criança é única, o problema de aprendizagem está relacionado a individualidade de quem aprende. A reação de cada criança, diante das dificuldades que intervêm na sua aprendizagem, é diferente. Cabe ao professor, olhar para os seus alunos de forma primordial, pois é ele que dará os primeiros passos para que o sofrimento do seu aluno não continue causando desconfortos futuros. Por isso, identificar seu problema, ajudará a conhecer seus pontos fortes e fracos buscando estratégias que permitam ter sucesso na sua aprendizagem. De acordo com Campos (1979),

A aprendizagem envolve o uso e o desenvolvimento de todos os poderes, capacidades, potencialidades do homem, tanto físicas, quanto mentais e afetivas, isto significa que aprendizagem não pode ser considerada somente como um processo de memorização ou que emprega apenas o conjunto das funções mentais ou unicamente os elementos físicos ou emocionais, pois todos estes são aspectos necessários. (CAMPOS, 1979, p. 33).

Quanto mais cedo for a mediação, a criança poderá aprender a direcionar as dificuldades de seu aprendizado. É importante a utilização de uma metodologia e didática diferenciada, com a finalidade de recuperar conceitos não adquiridos, tornando esta criança, na medida do possível, leitores e escritores competentes. Pois "uma coisa é a criança que não quer aprender a ler, outra é a criança que não pode aprender a ler com os métodos pedagógicos tradicionais. Não podemos assumir 
atitudes reducionistas que afirmam que a dislexia não existe". (FONSECA, 1995, p. 12)

As dificuldades de aprendizagem que as crianças apresentam na infância têm sempre um impacto sobre sua vida no futuro, tanto deles como de seus familiares e em seu entorno, pois, se essas dificuldades não forem mediadas poderão implicar prejuízos em todas as áreas do desenvolvimento pessoal e social.

\subsubsection{CAUSAS DAS DIFICULDADES E O PAPEL DO PROFESSOR}

Compreender as dificuldades de aprendizagem na alfabetização, exigi uma análise minuciosa e consciente do professor. Muitos fatores podem interferir no processo de ensino-aprendizagem dos educandos, os problemas e as necessidades vivenciadas entre os docentes fora da escola, podem vir a intervir na aprendizagem dos mesmos. É necessário ter conhecimento para compreender as causas dessas dificuldades de aprendizagem do aluno, e analisando essa dificuldade, observar como isto está sucedendo e o tempo que isto acontece, se é por causa de uma dificuldade exclusiva do aluno. Deve-se respeitar ainda, o contexto social e familiar da criança, depois disso pode se tomar atitudes necessárias para que a criança tenha grandes possibilidades de aprender.

A educação recebida, na escola, e na sociedade de um modo geral cumpre um papel primordial na constituição dos sujeitos, a atitude dos pais e suas práticas de criação e educação são aspectos que interferem no desenvolvimento individual e consequentemente o comportamento da criança na escola. (VYGOTSKY, 1984, p.87).

A presença de uma dificuldade de aprendizagem necessariamente não implica em um Transtorno de Aprendizagem. Os Transtornos de Aprendizagem compreendem uma inabilidade específica com a leitura, escrita e matemática em indivíduos que apresentam processo significativo abaixo do nível de desenvolvimento escolar e capacidade intelectual.

Os Transtornos de Aprendizagem, como a discalculia, dislexia, entre outros, interferem no processo de aquisição e cuidados necessários de informações, 
provocando perturbações no aprender da criança do que as complexidades de conhecimento.

As causas das dificuldades de aprendizagem estão relacionadas normalmente a fatores que interferem no aprendizado da criança, como problema com a escola, falta de habilidade do professor, falta de estímulos para motivação do aluno e fatores relacionados à família.

- Causas relacionadas à escola: As salas de aulas superlotadas de alunos a ponto de o professor passar mais tempo gerenciando a sala do que realmente ensinando, isso pode contribuir para que os alunos comecem a apresentar dificuldades de aprendizagem.

- Falta de habilidade do professor: O professor desempenha um papel importante no desempenho dos alunos e pode ser responsável pelas dificuldades. Se o professor é inexperiente ou não atua na sua profissão com amor, a criança pode sentir dificuldade em desenvolver a compreensão da atividade que está sendo desenvolvida. $O$ autoritarismo do professor pode contribuir para que o aluno não ponha as suas habilidades em práticas.

- Falta de estímulos para motivação do aluno: Muitas vezes, a falta de aprendizagem parte do educando. Uma deficiência na aprendizagem é um fator que o aluno possui criando obstáculos para conseguir chegar ao mesmo nível de aprendizagem dos outros. A falta de motivação do aluno é outro fator de baixo rendimento, nesse caso é necessário que o aluno receba essa motivação dos pais.

- Fatores relacionados às famílias: Os pais não se importam ou estão muito ausentes por não haver tempo para cuidar dos seus filhos, e eles acabam perdendo o foco nos estudos. Muitas vezes as crianças moram em local com pobreza, onde a sobrevivência se torna mais importante do que a escola. Famílias desestruturadas prejudicam o aprendizado.

O papel do professor diante das dificuldades se limita em observar o aluno e auxiliar o seu processo de ensino aprendizagem, criar e desenvolver situações que possibilite relações harmoniosas entre todas as pessoas envolvidas. O professor deve incentivar 
o interesse do aluno, influenciar a motivação, informando-lhe sobre a sua capacidade, propondo questões que ajudem-no a solidificar as que já possui e a construir competências para novas descobertas de maneira que tudo que foi aprendido na escola, possa ter significado fora dela.

No processo ensino-aprendizagem são construídas relações cognitiva e afetiva. Conforme Piaget (2014) relata que

é inegável a existência de uma constante interação entre a afetividade e a inteligência, podendo envolver significações distintas. O primeiro sentido mencionado em seu livro fala acerca do fato de que a afetividade interfere nas operações da inteligência, que ela as estimula ou as perturba, que é a causa de acelerações ou retardos no desenvolvimento intelectual, mas que não pode modificar as estruturas da inteligência como tais. (PIAGET, 2014, p. 37)

No processo de aprendizagem é indiscutivelmente as atitudes do professor, em seus conceitos e ações, que serão as causas decisivas no sucesso ou fracasso escolar dos educandos. Compete ao educador duas funções básicas diante das necessidades de aprendizagem: a análise ou constatação seguida de interferência adequada. Segundo Morais (2002, p. 188), "(...) é de suma importância já que, permite que se estabeleça, entre o professor e o aluno, um clima aberto e sincero, no qual a criança se sente apoiada e tranquila sobre as possíveis reações do professor frente às suas dificuldades."

Os estímulos são imprescindíveis, pois funcionarão como apoio à autoestima, que progressivamente levará o aluno a acreditar em si mesmo e na sua capacidade para superar as dificuldades. No dizer de Freire (2007),

São professores sem receio de expressar sua afetuosidade, pois é preciso não ter medo do carinho [...]. Só os mal-amados e as malamadas entendem a atividade docente como um que fazer de insensíveis, de tal maneira cheios de racionalismo que se esvaziam de vida e de sentimentos. (FREIRE, 2007, p. 69).

É necessário que a relação entre professor e aluno não seja apenas profissional, mais, que o professor demostre uma relação de afetividade com os seus alunos. Essa afetividade contribuirá para motivar no aluno o desejo de aprender. 


\section{CONSIDERAÇÕES FINAIS}

A realização desta pesquisa foi bastante desafiadora e proveitosa, e o conhecimento adquirido desta, para atuar na minha prática pedagógica, será muito significante. Ao longo desta pesquisa foi estudado diferentes teóricos que promoveram o desenvolvimento da dificuldade de aprendizagem na leitura e na escrita nos anos iniciais do ensino fundamental. A transmissão da leitura e da escrita deve começar cedo na vida da criança, quanto antes ela se apoderar dessa competência, mais poderá desenvolvê-la com êxito, sendo capaz de utilizá-la com facilidade na sociedade a qual está inserida.

A dificuldade de aprendizagem na leitura e na escrita merece atenção dos professores, pois, são eles que primeiramente poderão identificar a dificuldade do aluno. O professor é aquele com melhores condições de conhecer a dificuldade do aluno por conviver mais próximo, do seu desenvolvimento intelectual e cognitivo.

Além da família, a escola é também um responsável pela integração da criança na sociedade. O professor precisa estar sempre inovando e aprimorando seus conhecimentos e ter consciência de que uma atitude negativa pode causar transtornos para vida inteira. Portanto, o professor precisa diferenciar e respeitar o ritmo de aprendizagem de cada aluno, pois a criança com dificuldades, geralmente, tem problemas de processamento das informações, necessitando de mais tempo para processá-las.

Os estudos realizados nesta pesquisa, possibilitou compreender que há muito a ser feito em relação as dificuldades de aprendizagem na leitura e na escrita, além de procurar utilizar metodologias adequadas para que a criança consiga desenvolver suas habilidades.

\section{REFERENCIAS}


A IMPORTÂNCIA DA LEITURA. Pedagogia ao Pé da Letra, 2013. Disponível em: $<$ https://pedagogiaaopedaletra.com/a-importancia-da-leitura/>. Acesso em: Acesso em: 21 nov. 2016.

BAMBERGER, Richard. Como incentivar o hábito da leitura. São Paulo: Editora Ática, 2002.

BRASIL. Parâmetros Curriculares Nacionais. Ensino Fundamental: Língua Portuguesa / Secretaria de Educação Fundamental. Brasília: MEC/SEF, 1997.

CAMPOS, Dinah Martins de Souza. Psicologia da aprendizagem. 11. Ed. Petrópolis: Vozes, 1979.

CRISTINE, Elen. A importância do hábito de ler. Mundo Educação, [s.d.] Educação. <http://www.mundoeducacao.bol.uol.com.br/educacao/a-importancia-habito-ler.htm>. Acesso em 22 nov. 2016.

DAVIS, Ronald D. O dom da dislexia. Rio de Janeiro: Rocco. 2004.

DROUET, Ruth Caribé da Rocha. Distúrbio de Aprendizagem. São Paulo: Ática, 2006.

FERREIRO, Emília. Com todas as letras. 4. ed. São Paulo: Cortez, 1993.

. O Processo de leitura e escrita: novas perspectivas. Porto Alegre: Artes Médicas, 1987.

. Passado e Presente dos Verbos Ler e Escrever. São Paulo: Cortez, 2002.

Reflexões sobre alfabetização. Trad. Horácio Gonzáles et.al, 24르 ed. São Paulo: Cortez/Autores Associados, 2001.

FERREIRO, Emilia; Teberosk, Ana. A Psicogênese da Língua Escrita. Porto Alegre: Artes Médicas, 1985. 
FONSECA, Vitor da. Introdução às dificuldades de aprendizagem. 2. ed. Porto Alegre: Artmed, 1995. Disponível em: < www.diaadiaeducacao.pr.gov.br/portals/pde/ arquivos/2320-8.pdf>. Acesso em: 18 nov. 2016.

FREIRE, Paulo. A Educação na cidade. São Paulo: Cortez, 1991.

. A importância do ato de ler em três artigos que se completam. $23^{\mathrm{a}} \mathrm{ed}$. São Paulo: Cortez, 1989.

Pedagogia da Autonomia. 35. ed. São Paulo: Paz e Terra, 2007.

GONÇALVES, Debora Souza Neves. A importância da leitura nos anos iniciais escolares. 2013. 20 f. Monografia (Graduação em Pedagogia), Faculdade de Formação de Professores, Universidade do Estado do Rio de Janeiro. São Gonçalo, 2013. Disponível em: <http://www.ffp.uerj.br/arquivos/dedu/monografias/dsng.pdf>. Acesso em: 22 nov. 2016.

LEAL, Flavimilton. As dificuldades do ensino e aprendizagem no Ensino Fundamental I. Monografias Brasil Escola. [s.d]. Pedagogia. Disponível em: $<$ As dificuldades do ensino e aprendizagem no Ensino Fundamental I (uol.com.br)> Acesso em: 03 dez. 2012.

MARTINS, Maria Helena. O que é leitura. São Paulo: Brasiliense, 1982.

NICO, Maria Ângela Nogueira; SOUZA, José Carlos Ferreira. Nova definição da dislexia. 2003. Tradução e adaptação do "Annals of Dyslexia" volume 53, 2003. Disponível em: <professor.ufop.br/sites/default/files/danielmatos/files/a_nova_ definicao_de_dislexia.pdf>. Acesso em: 06 dez. 2016.

O professor e o aluno face a dificuldade de aprendizagem. Espaço Psicopedagógico, 19 jan. 2010. Disponível em: $<$ <ttp:www.espaopsicopedagogico.blogspot.com/.../o-professor-e-o-alunofacedificuldade.html>. Acesso em: 12 dez. 2016.

PIAGET, Jean. Estudos Sociológicos. Rio de Janeiro: Forense, 1973. 
RODRIGUES, Maria Zita; SILVEIRA, Leila. Dislexia: distúrbio de aprendizagem da leitura e escrita no Ensino Fundamental. 2008. Disponível em: <Dislexia: Distúrbio De Aprendizagem Da Leitura E Escrita No Ensino Fundamental (webartigos.com)>. Acesso em: 11 nov. 2016.

SHIMAZAKI, Elsa Midori. Causas das dificuldades na leitura e escrita. Disponível em: <http://www.gestaoescolar.diaadia.pr.gov.br/arquivos/.../artigo_elsa_midori_ shimaza ki.pdf>. Acesso em: 15 nov. 2016.

SILVA, Ezequiel Theodoro da. Conhecimento e cidadania: quando a leitura se impõe como mais necessária ainda! In: . Conferências sobre leitura: trilogia pedagógica. Campinas: Autores Associados, 2003. Disponível em: <http://www.reflexoessobrealeitura.pdf> Acessado em: 06 dez. 2016.

SOARES, Magda. Alfabetização e letramento. São Paulo: Editora Contexto, 2004. . Letramento: um tema em três gêneros, Belo Horizonte: Autêntica, 2001. Letrar é mais que alfabetizar. In: Nossa Língua-nossa pátria. Rio de Janeiro: Jornal do Brasil, 26/11/2000a. Entrevista. Disponível em: <http://www.intervox.nce.ufrj.br/ edpaes/magda.html>. Acesso em: 03 dez. 2016.

UNIVERSIDADE LUTERANA DO BRASIL. Psicologia do desenvolvimento e da aprendizagem. Curitiba: Afiliada, 2008.

VYGOSTSKY, Lev Semionovitch. A formação social da mente: o desenvolvimento dos processos psicológicos superiores. São Paulo: Martins Fontes, 1991.

. 6ª ed. São Paulo: Martins Fontes, 1987.

. São Paulo: Martins Fontes, 1984.

O desenvolvimento dos processos pedagógicos superiores.

Barcelona: Grijabo, 1979. 
Enviado: Outubro, 2020.

Aprovado: Novembro, 2020. 